\title{
PENGEMBANGAN MULTIMEDIA INTERAKTIF "SCRIBER" UNTUK PESERTA DIDIK SEKOLAH MENENGAH PERTAMA
}

\author{
Elviana Febrianti ${ }^{1}$, Neni Wahyuningtyas ${ }^{2}$, Nurul Ratnawati ${ }^{3}$ \\ ${ }^{1,2,3}$ Pendidikan IPS, Universitas Negeri Malang \\ Jalan Semarang Nomor 5, Sumbersari, Lowokwaru, Malang, Jawa Timur \\ 1email: elviana.febrianti.1707416@students.um.ac.id
}

\begin{tabular}{|c|c|c|c|c|c|}
\hline $\begin{array}{l}\text { Submitted } \\
2021-09-13\end{array}$ & $\begin{array}{c}\text { Accepted } \\
2021-11-23\end{array}$ & $\begin{array}{l}\text { Published } \\
2021-12-13\end{array}$ & open 2 ACcess & (c) $(i)$ () & asinta 3 \\
\hline
\end{tabular}

\begin{abstract}
Abstrak
Tujuan penelitian adalah mengembangkan multimedia interaktif "SCRIBER" (Social Studies Learning-Based Articulate Storyline) tentang Potensi Sumber Daya Alam dan Kemaritiman Indonesia yang valid dan efektif untuk digunakan dalam pembelajaran. Penelitian menggunakan metode penelitian dan pengembangan (R\&D) dengan model pengembangan penilaian dan analisis, desain, pengembangan, implementasi, dan evaluasi. Subjek penelitian yaitu 2 dosen dan 32 peserta didik. Validasi instrumen menggunakan angket validasi dan angket respons peserta didik yang menunjukkan produk yang dikembangkan layak. Teknik analisis data menggunakan deskriptif kualitatif dan kuantitatif dengan perhitungan skor menggunakan skala Likert dan Guttman. Hasil penelitian menunjukkan bahwa ahli media menyatakan bahwa produk yang dikembangkan termasuk pada kriteria sangat layak, penilaian materi termasuk pada kriteria sangat layak, respons peserta didik terhadap produk yang dikembangkan termasuk pada kriteria sangat baik, dan efektif digunakan dalam proses pembelajaran.
\end{abstract}

Kata Kunci: Articulate Storyline; multimedia interaktif; SCRIBER.

\begin{abstract}
The research aimed to develop interactive multimedia "SCRIBER" (Social Studies Learning-Based Articulate Storyline) about the Potential of Indonesian Maritime and Natural Resources valid and effective for use in learning. The research used the research and development $(R \& D)$ method with the analysis, design, development, implementation, and evaluation development model. The research subjects were 2 lecturers and 32 students. The validation of the research results was carried out by expert validators and students. The data analysis technique used descriptive qualitative and quantitative with the calculation of scores using the Likert and the Guttman scale. The results showed that the media experts stated that the developed product was included in the very feasible criteria, the material assessment included the very feasible criteria, the student's responses to the developed product included the very good criteria and the effectiveness obtained from the posttest results was higher than the pretest results.
\end{abstract}

Keywords: Articulate Storyline; interactive multimedia; SCRIBER.

\section{PENDAHULUAN}

Revolusi industri yang terjadi pada abad ke-21 menyebabkan teknologi semakin berkembang dan informasi banyak tersebar. Adanya revolusi abad ke-21 mampu menciptakan sumber daya manusia yang berkualitas dan memiliki daya 
saing tinggi dalam berbagai keterampilan. Penguasaan keterampilan seperti keterampilan penyelesaian masalah, berpikir kritis, bekerja sama, berkomunikasi, bersosialisasi, berkarier, dan menguasai teknologi menjadi hal penting dalam menghadapi abad ke-21 (Kuncahyo et al., 2020). Keterampilan abad ke-21 dapat terlaksana dengan memperbaiki kualitas pendidikan. Oleh karenanya, semua pihak di bidang pendidikan dituntut mampu menyesuaikan dengan kemajuan teknologi untuk meningkatkan kualitas pembelajaran (Ramdani et al., 2019).

Pencapaian keterampilan abad ke-21 telah disadari oleh Kementerian Pendidikan dan Kebudayaan Republik Indonesia dengan menyusun tiga konsep pembelajaran abad ke-21 melalui pengembangan Kurikulum 2013. Pembelajaran juga harus dikembangkan dengan menjadikan peserta didik sebagai pusat belajar (student-centered learning), menciptakan pembelajaran yang kontekstual, dan peserta didik harus mampu berkolaborasi dengan orang lain (Syahputra, 2018). Peran guru bukan lagi menjadi pusat belajar tetapi sebagai fasilitator dengan menyiapkan pembelajaran yang dapat mengembangkan keterampilan peserta didik yang diperlukan pada abad ke-21 (Ramdani et al., 2019).

Guru sebagai fasilitator dituntut memiliki kemampuan beraneka ragam dan harus memperbarui kemampuannya setiap waktu agar tidak ketinggalan zaman. Guru harus memiliki kemampuan Technological Pedagogical Content Knowledge atau singkatnya TPACK (Mansur et al., 2020). Komponen TPACK yang dapat dimanfaatkan guru dalam kegiatan pembelajaran adalah dengan menggunakan media pembelajaran. Penggunaan media berbasis teknologi dapat meningkatkan penguasaan materi dan keaktifan belajar peserta didik (Putriani, 2014). Kemampuan guru dalam penguasaan teknologi bertujuan untuk memberikan fasilitas terhadap peserta didik.

Berdasarkan hasil pengamatan dan wawancara terhadap guru Ilmu Pengetahuan Sosial (IPS) di SMP Negeri 8 Malang, diketahui bahwa guru belum memanfaatkan komponen TPACK dalam mengajar, guru masih sering menggunakan bahan ajar berupa Lembar Kerja Siswa (LKS) dan modul, sehingga antusias peserta didik dalam belajar mata pelajaran IPS kurang aktif. Media pembelajaran yang digunakan oleh guru hanya berupa PowerPoint biasa tanpa 
Edukasi: Jurnal Pendidikan, Volume 19 Nomor 2 Tahun 2021

Pengembangan Multimedia Interaktif "SCRIBER” untuk Peserta Didik.......

Elviana Febrianti, Neni Wahyuningtyas, Nurul Ratnawati

Halaman 275-289

disuguhkan gambar yang dapat menarik perhatian peserta didik. Media pembelajaran yang digunakan guru tidak melibatkan peserta didik secara langsung. Alternatif pemecahan masalah tersebut adalah menggunakan multimedia interaktif "SCRIBER" (Social Studies Learning-Based Articulate Storyline). Penggunaan multimedia interaktif dapat dijadikan sebagai alternatif media pembelajaran di sekolah karena dapat menunjang proses pembelajaran yang mampu meningkatkan hasil belajar peserta didik (Hakim \& Windayana, 2016). Pembelajaran menggunakan multimedia interaktif secara nyata dapat menunjang guru dalam menyampaikan materi (Jannah et al., 2019).

Multimedia interaktif dibuat menggunakan aplikasi Articulate Storyline. Aplikasi Articulate Storyline adalah aplikasi multimedia interaktif yang dapat diakses oleh guru atau peserta didik (Hadza et al., 2020). Articulate Storyline didukung dengan format HTML5 yang dapat dijalankan melalui komputer maupun smartphone secara online dan offline. Multimedia interaktif "SCRIBER" dengan konten gambar, video, dan animasi dapat memberikan pengetahuan yang konkret, lebih lengkap, dan kontekstual serta dapat dijalankan oleh peserta didik secara mandiri. Pemilihan inovasi media berupa multimedia interaktif "SCRIBER" diharapkan peserta didik menjadi aktif dalam proses pembelajaran.

Materi yang digunakan pada penelitian yang dilakukan adalah materi Potensi Sumber Daya Alam dan Kemaritiman Indonesia. Materi tersebut cakupannya sangat luas, bersifat abstrak, dan konsep materinya tidak bisa dihadirkan secara langsung dalam kelas serta sulit dikontekstualkan dengan lingkungan sekitarnya. Peneliti mengembangkan media pembelajaran yang mengarah pada kecanggihan teknologi berupa multimedia interaktif "SCRIBER" khususnya pada materi Potensi Sumber Daya Alam dan Kemaritiman Indonesia. Hasil penelitian digunakan untuk menghasilkan sebuah inovasi baru dalam kegiatan pembelajaran agar lebih efektif dan dapat dimanfaatkan guru memberikan fasilitas kepada peserta didik untuk membangun pengetahuan. Hal tersebut selaras dengan teori belajar konstruktivisme yaitu peserta didik aktif mencari tahu dan membangun pengetahuannya sendiri dan membuat pemahaman sendiri dari apa yang diperoleh (Rusman, 2012). 
Pembelajaran konstruktivisme berpusat pada peserta didik. Peran guru hanya menyediakan bahan belajar, mengarahkan peserta didik agar bisa memahami pengetahuannya, dan mengembangkan pembelajaran menggunakan teknologi (Sudarsana, 2018). Pembelajaran konstruktivisme merupakan pembelajaran yang diperoleh berdasarkan apa yang ada di sekitar peserta didik, kemudian diintegrasikan sendiri untuk membangun pengetahuan dan memiliki konsep berpikir (Rusman, 2012). Oleh karennay, tujuan penelitian adalah mengembangkan multimedia interaktif "SCRIBER" materi Potensi Sumber Daya Alam dan Kemaritiman di Indonesia untuk kelas VII SMP.

\section{METODE}

Metode yang digunakan dalam penelitian adalah penelitian dan pengembangan (research \& development) model Lee \& Owens dengan langkahlangkah yaitu penilaian dan analisis, desain, pengembangan, implementasi, dan evaluasi (Lee \& Owens, 2004). Peneliti menggunakan model pengembangan Lee \& Owens karena model pengembangan dikhususkan untuk mengembangkan multimedia interaktif. Penelitian dilakukan di SMP Negeri 8 Malang.

Tahap pertama penelitian yaitu penilaian dan analisis. Tahapan penilaian kebutuhan dilakukan peneliti dengan mewawancari dan mengobservasi guru serta peserta didik di SMP Negeri 8 Malang untuk menggali informasi terkait proses pembelajaran IPS. Tahapan analisis awal-akhir digunakan untuk menganalisis kebutuhan peserta didik, teknologi penunjang, situasi pembelajaran, permasalahan yang dialami peserta didik, dan media yang akan dikembangkan apakah sesuai dengan permasalahan peserta didik.

Tahap kedua adalah desain. Tahapan desain disesuaikan dengan analisis kebutuhan. Tahapan desain diawali dengan membuat spesifikasi produk media, materi, menyusun Rencana Pelaksanaan Pembelajaran (RPP), dan membuat produk. Spesifikasi disesuaikan dengan unsur multimedia interaktif berupa interaktivitas, interface, audio, dan video. Selanjutnya penyusunan RPP yang dijadikan sebagai acuan materi pembelajaran yang akan dimasukkan dalam multimedia interaktif "SCRIBER". 
Tahap ketiga adalah pengembangan. Pembuatan aplikasi dilakukan dengan menggabungkan beberapa komponen seperti video, animasi, gambar, materi, musik, dan soal. Tahap keempat adalah melakukan penilaian. Penilaian dilakukan oleh validator (ahli) serta menambahkan masukan validator melalui revisi sebelum diujicobakan. Langkah selanjutnya melakukan uji coba kepada peserta didik. Tahap kelima adalah evaluasi terhadap angket yang telah diisi oleh peserta didik. Hasil evaluasi dijadikan acuan sebagai revisi multimedia interaktif agar dinyatakan valid. Subjek penelitian adalah 32 peserta didik kelas VII sebagai responden, 4 orang validator untuk menilai kebenaran materi, soal evaluasi, dan konsep multimedia interaktif "SCRIBER". Validator terdiri dari ahli media pembelajaran dan ahli materi.

Instrumen penelitian menggunakan angket validasi dan angket respons peserta didik. Angket validasi meliputi validasi materi dan media. Kisi-kisi instrumen angket validasi materi (Akbar, 2017) disajikan di Tabel 1 dan kisi-kisi angket validasi media (Akbar, 2017) disajikan di Tabel 2. Angket respons peserta didik digunakan pada tahap uji coba. Kisi-kisi angket respons peserta didik (Akbar, 2017) disajikan di Tabel 3.

Tabel 1 Kisi-Kisi Instrumen Angket Validasi Materi

\begin{tabular}{|c|c|}
\hline Aspek & Indikator \\
\hline $\begin{array}{l}\text { Kelayakan } \\
\text { isi }\end{array}$ & $\begin{array}{l}\text { Materi relevan dengan kompetensi peserta didik. } \\
\text { Kejelasan materi yang disampaikan. } \\
\text { Keruntutan materi. } \\
\text { Kesesuaian perkembangan kognitif dan tingkat kesulitan peserta didik. } \\
\text { Latihan soal sesuai kompetensi. } \\
\text { Kesesuaian materi dan kebutuhan peserta didik. } \\
\text { Kelengkapan materi. } \\
\text { Kesesuaian pemberian contoh materi. }\end{array}$ \\
\hline Bahasa & $\begin{array}{l}\text { Bahasa informatif dan komunikatif. } \\
\text { Kesesuaian tingkat kognitif dengan bahasa. }\end{array}$ \\
\hline Visualisasi & $\begin{array}{l}\text { Gambar sesuai materi. } \\
\text { Video sesuai materi. }\end{array}$ \\
\hline $\begin{array}{l}\text { Soal } \\
\text { Evaluasi }\end{array}$ & $\begin{array}{l}\text { Pertanyaan sesuai dengan materi yang disajikan. } \\
\text { Kesesuaian kunci jawaban. } \\
\text { Pertanyaan disesuaikan dengan tingkat kemampuan peserta didik. }\end{array}$ \\
\hline
\end{tabular}


Tabel 2 Kisi-Kisi Instrumen Angket Validasi Media

\begin{tabular}{|c|c|}
\hline Aspek & Indikator \\
\hline $\begin{array}{c}\text { Komponen } \\
\text { multimedia } \\
\text { interaktif } \\
\text { "SCRIBER" }\end{array}$ & $\begin{array}{l}\text { Kemenarikan tampilan pembuka. } \\
\text { Kesesuaian judul dengan isi multimedia interaktif. } \\
\text { Kejelasan petunjuk. } \\
\text { Kelengkapan identitas multimedia interaktif. } \\
\text { Kemenarikan desain multimedia interaktif. }\end{array}$ \\
\hline $\begin{array}{l}\text { Pengorganisasi } \\
\text { tampilan }\end{array}$ & $\begin{array}{l}\text { Kemudahan penggunaan tombol. } \\
\text { Jenis huruf dan ukuran mudah dibaca. } \\
\text { Desain tampilan warna menarik. } \\
\text { Tata letak sesuai dan menarik. } \\
\text { Aransemen lagu menarik. }\end{array}$ \\
\hline Keinteraktifan & $\begin{array}{l}\text { Bahasa menarik dan mudah dipahami. } \\
\text { Penggunaannya melibatkan peserta didik. }\end{array}$ \\
\hline $\begin{array}{l}\text { Penilaian secara } \\
\text { keseluruhan }\end{array}$ & $\begin{array}{l}\text { Kemampuan multimedia interaktif menarik perhatian peserta didik. } \\
\text { Kemampuan multimedia interaktif sebagai sumber belajar. } \\
\text { Kemampuan multimedia interaktif disesuaikan dengan kebutuhan } \\
\text { peserta didik. } \\
\text { Kemampuan multimedia interaktif mendukung tercapainya } \\
\text { kompetensi. }\end{array}$ \\
\hline
\end{tabular}

Tabel 3 Kisi-Kisi Angket Respons Peserta Didik

\begin{tabular}{cl}
\hline Aspek & \multicolumn{1}{c}{ Indikator } \\
\hline Komponen & Tampilan mulitimedia interaktif. \\
multimedia & Kesesuaian isi materi dalam mulitimedia interaktif. \\
interaktif & Animasi yang disajikan dalam mulitimedia interaktif. \\
"SCRIBER" & Kejelasan objek gambar pada mulitimedia interaktif. \\
& Musik sudah sesuai dengan mulitimedia interaktif. \\
Pengorganisasi & Materi yang disajikan dapat dipahami dengan mudah. \\
tampilan & Desain multimedia interaktif dan warna menarik. \\
& Tata letak multimedia interaktif sesuai dan menarik. \\
& Aransemen lagu yang digunakan menarik. \\
& Tombol atau navigasi mudah digunakan pada mulitimedia interaktif. \\
Penyajian & Kemudahan memahami materi pada multimedia interaktif. \\
materi & Bahasa yang disajikan jelas dan komunikatif. \\
& Gambar yang disajikan menarik. \\
& Teks pada mulitimedia interaktif. \\
& Contoh disajika sama dengan materi yang diberikan. \\
& Soal yang disajikan sesuai dengan materi yang diajarkan. \\
& Kemudahan pengoperasian mulitimedia interaktif. \\
Penilaian secara & Mulitimedia interaktif menarik perhatian. \\
keseluruhan & Mulitimedia interaktif mampu membimbing dalam kegiatan \\
& pembelajaran. \\
& Petunjuk penggunaan mulitimedia interaktif mudah dipahami. \\
& Mulitimedia interaktif dapat digunakan berulang kali untuk belajar. \\
& Multimedia interaktif dapat menimbulkan motivasi belajar. \\
& Multimedia mulitimedia interaktif ini bermanfaat.
\end{tabular}


Multimedia interaktif "SCRIBER" diujicobakan kepada peserta didik. Data dianalisis menggunakan teknik analisis deskriptif kualitatif dan kuantitatif. Persentase angket validasi dihitung menggunakan perhitungan skor menurut skala Likert. Kriteria skala Likert (Ridwan, 2011) disajikan di Tabel 4.

\section{Tabel 4 Kriteria Skala Penilaian}

\begin{tabular}{cc}
\hline Kriteria & Skor \\
\hline Sangat baik & 4 \\
Baik & 3 \\
Cukup baik & 2 \\
Sangat tidak baik & 1 \\
\hline
\end{tabular}

Hasil persentase angket validasi dihitung dengan rumus (1) (Sanjaya, 2013).

$$
K=\frac{F}{N \times I \times R} \times 100 \%
$$

Keterangan: $\mathrm{K}$ adalah persentase validasi; $\mathrm{F}$ adalah total keseluruhan jawaban responden; $\mathrm{N}$ adalah skor penilaian tertinggi dalam angket; I adalah total pertanyaan dalam angket; $\mathrm{R}$ adalah jumlah responden.

Berdasarkan hasil perhitungan angket menggunakan rumus tersebut diperoleh kesimpulan kelayakan multimedia interaktif "SCRIBER" menggunakan kriteria skala Likert yang dapat dilihat di Tabel 5.

\begin{tabular}{cc}
\multicolumn{2}{c}{ Tabel 5 Kriteria Validitas Produk } \\
\hline Persentase (\%) & Kriteria \\
\hline $0-20$ & Sangat tidak layak \\
$21-40$ & Tidak layak \\
$41-60$ & Cukup layak \\
$61-80$ & Layak \\
$81-100$ & Sangat Layak \\
\hline
\end{tabular}

Angket respons peserta didik dihitung berdasarkan skala Guttman. Kriteria skala Guttman (Ridwan, 2011) disajikan di Tabel 6.

\section{Tabel 6 Kriteria Skala Guttman}

\begin{tabular}{cc}
\hline Jawaban & Skor \\
\hline Ya $(\mathrm{Y})$ & 1 \\
Tidak $(\mathrm{T})$ & 0 \\
\hline
\end{tabular}

Hasil persentase angket respons peserta didik dihitung menggunakan rumus (2) (Sanjaya, 2013). 


$$
K=\frac{F}{N \times I \times R} \times 100 \%
$$

Keterangan: $\mathrm{K}$ adalah persentase kriteria kelayakan; $\mathrm{F}$ adalah jumlah keseluruhan jawaban responden; $\mathrm{N}$ adalah skor tertinggi dalam angket; I adalah jumlah pertanyaan dalam angket; $\mathrm{R}$ adalah jumlah responden.

Hasil dari analisis data angket respons peserta didik kemudian dikonversi dalam kriteria penilaian (Ridwan, 2011) yang dapat dilihat di Tabel 7.

\section{Tabel 7 Kriteria Penilaian Data}

\begin{tabular}{cc}
\hline Persentase (\%) & Kriteria \\
\hline $0-20$ & Sangat tidak baik \\
$21-40$ & Tidak baik \\
$41-60$ & Cukup baik \\
$61-80$ & Baik \\
$81-100$ & Sangat baik \\
\hline
\end{tabular}

Keefektifan produk diperoleh dengan membandingkan nilai yang diperoleh saat posttest dan pretest setelah peserta didik menggunakan multimedia interaktif "SCRIBER" sebagai media pembelajaran. Apabila hasil posttest lebih baik dibandingkan hasil pretest, maka dapat diambil kesimpulan bahwa multimedia interaktif "SCRIBER" efektif digunakan sebagai media pembelajaran.

\section{HASIL DAN PEMBAHASAN}

Tahap awal pengembangan multimedia interaktif "SCRIBER" adalah penilaian dan analisis yang terbagi menjadi dua tahapan penilaian kebutuhan (need assesment) dan analisis awal-akhir (front analysis). Hasil analisis yang dilakukan di SMP Negeri 8 Malang menunjukkan bahwa materi Potensi Sumber Daya Alam dan Kemaritiman di Indonedia merupakan materi kompleks yang sulit dikuasai oleh peserta didik, masih banyak guru yang kesulitan dalam membuat media pembelajaran, pemanfaatan laboratorium dalam pembelajaran IPS belum dilakukan secara maksimal, dan belum ada multimedia interaktif yang dikembangkan dalam membahas materi Potensi Sumber Daya Alam dan Kemaritiman di Indonesia.

Tahap kedua adalah desain. Produk dirancang setelah melakukan analisis agar produk yang dikembangkan sesuai dengan kebutuhan pengguna. Desain produk diawali dengan menyusun storyboard yang berfungsi sebagai desain awal 
tampilan multimedia interaktif "SCRIBER". Langkah selanjutnya melakukan modifikasi layout pada produk yang dikembangkan. Storyboard terlihat di Gambar 1. Materi Potensi Sumber Daya Alam dan Kemaritiman di Indonesia untuk kelas VII semester 1 dimasukkan dan disajikan dalam multimedia interaktif "SCRIBER". RPP juga disusun dalam tahap desain agar pembelajaran terlaksana sesuai dengan tujuan pembelajaran, yaitu menjelaskan potensi sumber daya alam berupa hutan di Indonesia, potensi sumber daya alam berupa tambang di Indonesia, dan potensi kemaritiman di Indonesia.

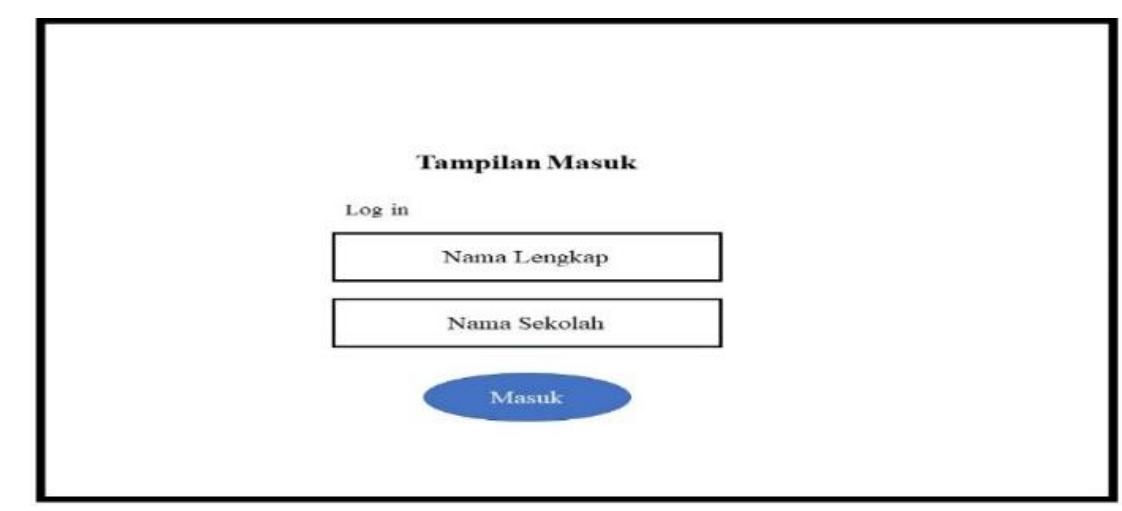

\section{Gambar 1 Tampilan Awal}

Tahap ketiga adalah pengembangan. Pengembangan dilakukan setelah perancangan desain kemudian dilanjutkan dengan membuat tampilan multimedia interaktif "SCRIBER" yang dibuat menggunakan aplikasi Articulate Storyline. Hasil multimedia interaktif "SCRIBER" berupa file HTML5 yang bisa dijalankan melalui smartphone dan komputer. Tampilan multimedia interaktif "SCRIBER" dirancang semenarik mungkin. Tampilan multimedia interaktif disesuaikan dengan aspek yang telah ditentukan dan unsur-unsur yang ada dalam multimedia interaktif. Sebagai contoh, interaktivitas yang terdapat pada aplikasi, interface yang tertera pada gambar, dan animasi yang berisi menu yang ketika diklik akan menampilkan isi dari menu yang dinginkan, audio, dan video.

Tampilan hasil pengembangan multimedia interaktif "SCRIBER" yaitu tampilan awal membuka multimedia interaktif "SCRIBER" akan muncul tampilan $\log$ in yang berisi nama peserta didik dan asal sekolah. Tampilan selanjutnya berisi judul konten materi yang akan digunakan dalam proses pembelajaran. Kemudian peserta didik disajikan tampilan menu materi yang akan dipelajari. 
Tampilan tersebut didalamnya terdapat penjelasan materi, contoh, dan soal evaluasi. Tampilan hasil pengembangan multimedia interaktif "SCRIBER" terlihat di Gambar 2.

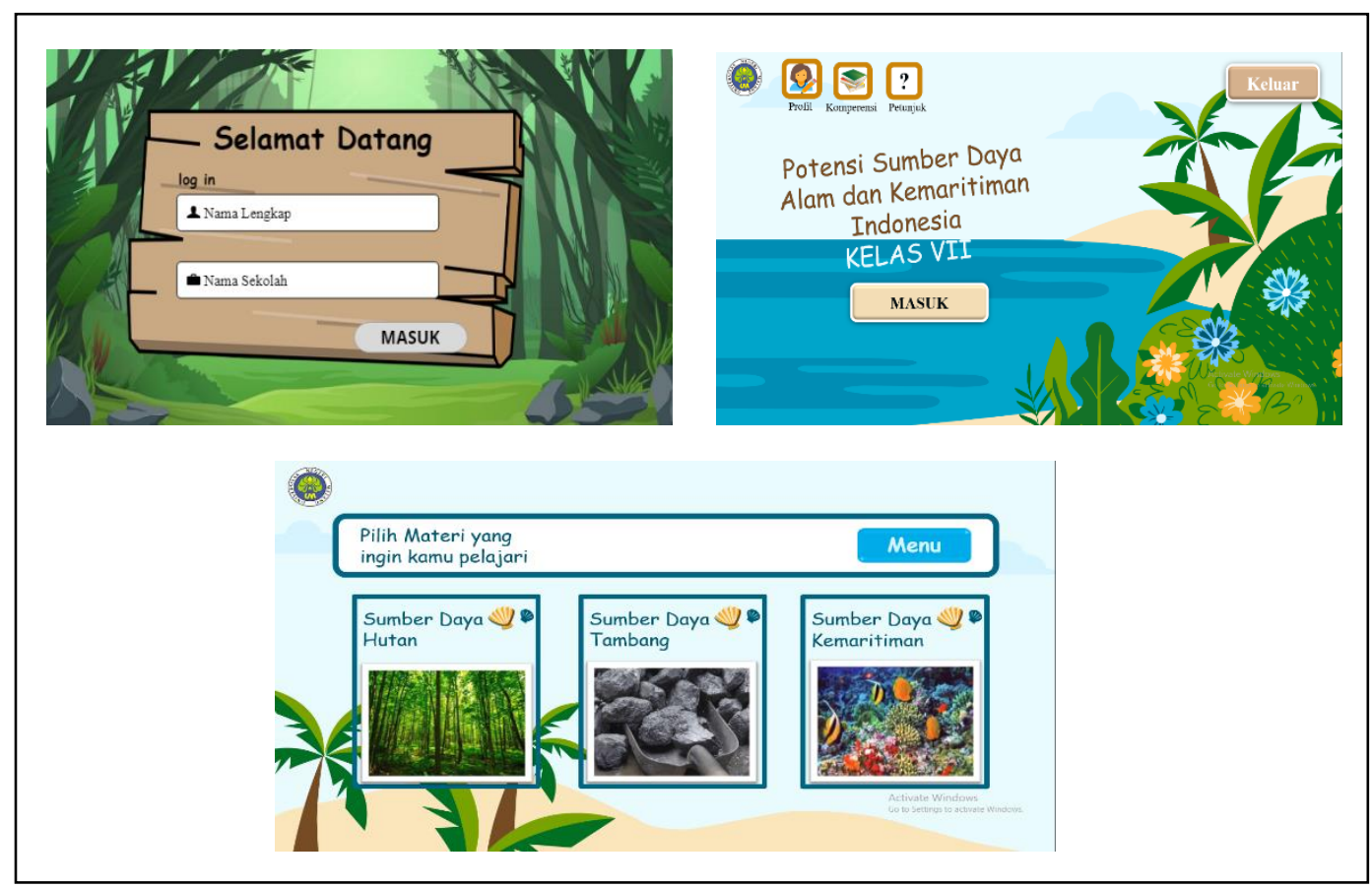

Gambar 2 Tampilan Multimedia Interaktif "SCRIBER"

Setelah produk selesai dikembangkan, maka selanjutnya dilakukan validasi ahli. Validasi dilakukan untuk mengetahui relevansi materi dan desain produk yang dapat diketahui kelayakannya sebelum dilakukan uji coba kepada peserta didik. Rekapitulasi data validasi ahli dapat dilihat di Tabel 8.

\begin{tabular}{cccc}
\multicolumn{4}{c}{ Tabel 8 Hasil Validasi Ahli Media dan } \\
\hline Ahli & Total Skor & Rata-Rata & Kriteria \\
\hline Materi 1 & 58 & $90,62 \%$ & Sangat Layak \\
Materi 2 & 56 & $87,5 \%$ & Sangat Layak \\
Media 1 & 59 & $92,18 \%$ & Sangat Layak \\
Media 2 & 55 & $85,94 \%$ & Sangat Layak \\
\hline
\end{tabular}

Berdasarkan Tabel 8, terlihat bahwa Materi Potensi Sumber Daya Alam dan Kemaritiman di Indonesia sesuai dengan kompetensi peserta didik. Penyampaian soal dan materi melalui multimedia interaktif "SCRIBER" mempermudah peserta didik dalam memahami materi pembelajaran. Rata-rata hasil penilaian validator memperoleh kriteria pencapaian Sangat Layak. Hasil penilaian produk yang 
Edukasi: Jurnal Pendidikan, Volume 19 Nomor 2 Tahun 2021

Pengembangan Multimedia Interaktif "SCRIBER” untuk Peserta Didik.......

Elviana Febrianti, Neni Wahyuningtyas, Nurul Ratnawati

Halaman 275-289

mencapai nilai $81 \%-100 \%$ dapat diimplementasikan secara langsung tanpa melakukan revisi (Sugiyono, 2017). Hasil validasi terdapat beberapa catatan komentar dan saran validator, maka peneliti melakukan revisi sebelum digunakan untuk uji coba pada peserta didik.

Tahap keempat adalah implementasi. Setelah produk selesai dikembangkan kemudian diujicobakan pada sasaran pengguna. Uji coba dilakukan untuk mencari data respons peserta didik. Penilaian pada tahap uji coba menggunakan soal pretest dengan hasil nilai yang diperoleh rata-rata 80 . Kemudian peserta didik diminta untuk memahami cara menggunakan multimedia interaktif "SCRIBER". Setelah peserta didik menggunakan multimedia interaktif "SCRIBER" kemudian peserta didik diberikan angket penilaian.

Berdasarkan hasil penilaian angket yang diisi peserta didik, persentase skor yang diperoleh sebesar 94,34\% dengan kriteria Sangat Layak. Kesimpulannya peserta didik dapat dengan mudah memahami materi melalui multimedia interaktif "SCRIBER". Setelah peserta didik diberikan materi menggunakan multimedia interaktif "SCRIBER" kemudian diberikan evaluasi berupa posttest. Hasil posttest peserta didik memperoleh nilai rata-rata sebesar 91. Nilai posttest lebih besar dari nilai pretest yang menunjukkan bahwa multimedia interaktif "SCRIBER" efektif digunakan dalam proses pembelajaran dan berpengaruh terhadap hasil belajar peserta didik. Hasil yang diperoleh peneliti sesuai dengan penelitian terdahulu yang menyatakan hasil belajar peserta didik dikatakan efektif apabila hasil posttest lebih tinggi dari hasil pretest (Arifin \& Aprisal, 2020). Sesuatu dapat dikatakan efektif apabila mampu mendapat gambaran mengenai keberhasilan dari seseorang untuk mencapai sasaran dari tujuan yang ingin dicapai (Darmawan, 2014).

Tahap kelima adalah evaluasi. Produk yang dikembangkan telah melalui proses evaluasi yang panjang mulai dari validator media, validator materi, dan uji coba sasaran pengguna. Saran dan kritik pada produk penelitian, yaitu produk yang dikembangkan tulisannya belum rapi. Video yang disajikan terlalu panjang, gambar kurang jelas, dan belum mencantumkan sumber referensi. Berdasarkan respons peserta didik dengan menggunakan multimedia interaktif "SCRIBER" 
membuat lebih cepat memahami dan mengingat materi. Pemanfaatan multimedia interaktif dalam proses pembelajaran dapat menghemat waktu dan meningkatkan memori peserta didik (Jannah et al., 2019). Multimedia interaktif dalam proses pembelajaran memiliki kegunaan yang sangat baik karena mampu mengkomunikasikan informasi agar peserta didik mengembangkan keterampilan dan meningkatkan kegiatan pembelajaran (Widayat et al., 2014).

Multimedia interaktif "SCRIBER" didesain dengan menggabungkan beberapa komponen seperti animasi, video, gambar, audio, dan tulisan yang dapat mempermudah peserta didik mengoperasikannya. Multimedia interaktif merupakan beberapa gambar, animasi, video, tulisan, dan audio yang dioperasikan sendiri oleh peserta didik (Handayani et al., 2018). Pengembangan multimedia interaktif dapat menciptakan interaksi dua arah, yaitu antara pengguna dan medianya sehingga tidak membuat cepat jenuh. Selaras dengan penelitian yang menyatakan pembelajaran menggunakan multimedia interaktif mampu meningkatkan pemahaman konsep peserta didik (Arda et al., 2015). Penggunaan multimedia di kelas dapat meningkatkan pemahaman, minat, dan kemampuan menghafal peserta didik (Gilakjani, 2012).

Pengembangan multimedia interaktif memanfaatkan teknologi komputer dan smartphone. Pemanfaatan teknologi dalam pembelajaran secara tidak langsung membuat peserta didik tertarik mengikuti proses pembelajaran dibandingkan dengan pembelajaran konvensional (Vernadakis et al., 2012). Pembelajaran yang memanfaatkan aplikasi Articulate Storyline mempunyai dampak positif. Pembelajaran secara konvensional dapat meningkatkan hasil belajar dengan skor bagus hanya $32 \%$ peserta didik dan sekitar $10 \%$ persen peserta didik melakukan remedial, sedangkan menggunakan aplikasi Articulate Storyline hanya sekitar 5\% peserta didik dengan nilai rendah dan $95 \%$ peserta didik sesuai dengan Kurikulum 2013 (Yumini \& Rakhmawati, 2015).

\section{SIMPULAN}

Produk yang berhasil dikembangkan adalah multimedia interaktif "SCRIBER" (Social Studies Learning-Based Articulate Storyline) untuk kelas VII 
pada materi Potensi Sumber Daya Alam dan Kemaritiman Indonesia. Berdasarkan hasil penelitian, disimpulkan bahwa hasil uji validasi yang dilakukan oleh ahli media dan ahli materi berada pada kategori Sangat Layak sehingga media pembelajaran dapat membantu dalam penyampaian materi kepada peserta didik dan kualitas materi yang disampaikan sesuai dengan kurikulum. Hasil penilaian angket uji coba peserta didik berada pada kategori Sangat Baik sehingga media yang dikembangkan memperoleh respons baik dari peserta didik. Penggunaan produk yang dikembangkan juga meningkatkan hasil belajar peserta didik yang dilihat dari hasil pretest dan posttest dengan kategori efektif sehingga dapat diterapkan dalam proses pembelajaran.

\section{DAFTAR PUSTAKA}

Akbar, S. (2017). Instrumen Perangkat Pembelajaran. Bandung: PT Remaja Rosdakarya.

Arda, Saehana, \& Sahrul, D. (2015). Pengembangan Media Pembelajaran Interaktif Berbasis Komputer untuk Siswa SMP Kelas VIII. Mitra Sains, 3(1), 69-77.

Arifin, S., \& Aprisal. (2020). Penerapan Model Pembelajaran Kooperatif Tipe Pair Checks terhadap Pemecahan Masalah Matematika. Jurnal Pendidikan Matematika, 11(1), 89-98.

Darmawan, D. (2014). Efektifitas Penggunaan Multimedia Interaktif (MMI) Model Tutorial terhadap Motivasi serta Hasil Belajar Peserta Didik pada Materi Elajaran Ilmu Pengetahuan Alam Pokok Bahasan Sistem Pernapasan Manusia. Edutech, 1(3), 386-399.

Gilakjani, A. P. (2012). The significant Role of Multimedia in Motivating EFL Learners' Interest in English Language Learning. International Journal of Modern Education and Computer Science, 4(4), 57-66.

Hadza, C., Sesrita, A., \& Suherman, I. (2020). Development of Learning Media Based on Articulate Storyline. Indonesian Journal of Applied Research (IJAR), 1(2), 80-85. https://doi.org/10.30997/ijar.v1i2.54.

Hakim, A. R., \& Windayana, H. (2016). Pengaruh Penggunaan Multimedia 
Interaktif dalam Pembelajaran Matematika untuk Meningkatkan Hasil Belajar Siswa SD. EduHumaniora Jurnal Pendidikan Dasar Kampus Cibiru, 4(2), 1-13. https://doi.org/10.17509/eh.v4i2.2827.

Handayani, E. S., Sikhabuden, \& Praherdhiono, H. (2018). Pengembangan Multimedia Interaktif Seni Tari Jawa Timur pada Mata Pelajaran Seni Budaya Kelas VII di SMP Negeri 1 Karangan. JKTP Jurnal Kajian Teknologi Pendidikan, 1(1), 63-70.

Jannah, M., Copriady, J., \& Rasmiwetti, R. (2019). Development of Interactive Learning Media Using Autoplay Media Studio 8 for Colloidal Chemistry Material. Journal of Educational Sciences, 3(1), 132-144. https://doi.org/10.31258/jes.3.1.p.132-144.

Kuncahyo, Suwandayani, B. I., \& Muzakki, A. (2020). Aplikasi E-Test "That Quiz” sebagai Digitalisasi Keterampilan Pembelajaran Abad 21 di Sekolah Indonesia. Lectura: Jurnal Pendidikan, 11(2), 153-166.

Lee, W. W., \& Owens, D. L. (2004). Multimedia Based Instructional Design: Second Edition. San Francisco: Pfeiffer.

Mansur, H., Mastur, \& Utama, A. H. (2020). Evaluasi Kemampuan Guru Melaksanakan Pembelajaran K-13 Berbasis TPACK Model Countenance Evaluation. International Journal of Innovation, Creativity and Change. $1(1), 1-10$.

Putriani, E. (2014). Implementasi Strategi TPCK dengan Media Simulasi Berbasis Inkuiri Terbimbing pada Konsep Getaran dan Gelombang. Unnes Physics Education Journal, 3(2), 35-41. https://doi.org/10.15294/upej.v3i2.3595.

Ramdani, A., Jufri, A. W., Gunawan, G., Hadisaputra, S., \& Zulkifli, L. (2019). Pengembangan Alat Evaluasi Pembelajaran IPA yang Mendukung Keterampilan Abad 21. Jurnal Penelitian Pendidikan IPA, 5(1), 98-108. https://doi.org/10.29303/jppipa.v5i1.221.

Ridwan. (2011). Skala Pengukuran Variabel-Variabel Penelitian. Bandung: Alfabeta.

Rusman. (2012). Model-model Pembelajaran: Mengembangkan Profesionalisme Guru. Depok: Raja Grafindo Persada. 
Sanjaya, W. (2013). Penelitian Pendidikan, Jenis, Metode dan Prosedur. Jakarta: Kencana Penada Media Group.

Sudarsana, I. (2018). Optimalisasi Penggunaan Teknologi dalam Impelementasi Kurikulum di Sekolah (Perspektif Teori Konstruktivisme). Celta: Jurnal Ilmu Pendidikan, 1(1), 8-15.

Sugiyono. (2017). Metode Penelitian Kuantitatif, Kualitatif, dan R\&D. Bandung: Alfabeta.

Syahputra, E. (2018). Pembelajaran Abad 21 dan Penerapannya di Indonesia. Prosiding Seminar Nasional SINASTEKMAPAN tahun 2018.

Vernadakis, N., Giannousi, M., Derri, V., Michalopoulos, M., \& Kioumourtzoglou, E. (2012). The Impact of Blended and Traditional Instruction in Students' Performance. Procedia Technology, 1(2012), 439443. https://doi.org/10.1016/j.protcy.2012.02.098.

Widayat, W., Kasmui, K., \& Sukaesih, S. (2014). Pengembangan Multimedia Interaktif sebagai Media Pembelajaran IPA Terpadu pada Tema Sistem Gerak pada Manusia. USEJ - Unnes Science Education Journal, 3(2), 535541. https://doi.org/10.15294/usej.v3i2.3353.

Yumini, S., \& Rakhmawati, L. (2015). Pengembangan Media Pembelajaran Interaktif Berbasis Articulate Storyline pada Mata Diklat Teknik Elektronika Dasar di SMK Negeri 1 Jetis Mojokerto. Jurnal Pendidikan Teknik Elektro, 4(3), 845-849. 